\title{
Inverted "upside-down" esophageal fully-covered self-expanding metal stent is effective for temporary treatment of colorectal strictures: a pilot case series
}

\section{(ㄷ)(우우}

\author{
Authors \\ Pier Alberto Testoni ${ }^{1}$, Lorella Fanti ${ }^{1}$, Enrico Antonucci ${ }^{2}$, Emanuele Dabizzi ${ }^{3}$
}

Institutions

1 Gastroenterology and Gastrointestinal Endoscopy Division, San Raffaele Scientific Institute, Vita-Salute San Raffaele University, Milan, Italy

2 Division of Surgical and Gastrointestinal Products, Euromedical s.r.I., San Zeno Naviglio, Italy

3 Pancreato-Biliary Endoscopy and Ultrasonography Division, San Raffaele Scientific Institute, Vita-Salute San Raffaele University, Milan, Italy

submitted 6.4.2018

accepted after revision 6.8 .2018

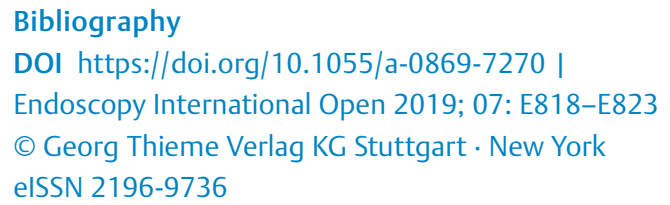

\section{Corresponding author}

Emanuele Dabizzi, MD, Pancreato-Biliary Endoscopy and Ultrasonography Division, San Raffaele Scientific Institute, Vita-Salute San Raffaele University, Via Olgettina 60,

20132 Milan, Italy

Fax: +39-02-2643-5609

emadabi@yahoo.it

\section{ABSTRACT}

Background and study aims Placement of a fully-covered self-expanding metal stent (FC-SEMS) is a valid alternative for benign and malignant colorectal strictures treatment. Despite the reportedly high technical success rate, stenting is still challenging, due to high rates of adverse events. Migration still represents the main issue, although several anti-migration systems have been proposed.

Patients and methods Before insertion, esophageal Beta Niti-S FC-SEMSs were inverted and reloaded on the deployment device to invert the proximal and distal parts of the stent, with the largest end placed above the stricture to contrast peristaltic activity. The inverted "upside-down" Beta Niti-S FC-SEMS was placed in five consecutive patients: four pts with benign anastomotic stricture unresponsive to repeated balloon dilation and persisting for at least 10 weeks, and one with malignant rectal neoplasia. In five patients, six inverted FC-SEMSs were placed.

Results The modified FC-SEMS did not migrate in $5 / 6$ cases (83\%). Stent migration occurred in the neoplastic case, induced by neoadjuvant chemotherapy. The "upside-down" esophageal Beta Niti-S FC-SEMS stayed in place for an average of 6 weeks, achieving resolution of stricture in all patients but one, who required an additional stent placement, due to incomplete stricture resolution after 6 weeks.

Conclusion The inverted esophageal Beta Niti-S FC-SEMSs proved to be effective in treating colorectal stricture in all cases, with no spontaneous migration or significant side effects, and achieved resolution of strictures where a traditional approach, recommended by guidelines, failed.

\section{Introduction}

Stent placement has become a safe and effective treatment for benign and malignant colorectal strictures. Self-expanding metal stents (SEMSs) have been widely used for both palliation or as a bridge-to-surgery approach for neoplastic strictures, and as an alternative or addition to balloon dilation for nonneoplastic strictures.
For benign strictures, fully-covered stents (FC-SEMSs) should be used, because they offer several potential advantages over uncovered stents in terms of reduced tissue ingrowth and overgrowth and easy removal [ $1-3]$, but results are still debated [4, 5]. Despite technical success rates reaching $100 \%$ in some studies, adverse events (AEs) are reported in up to $41 \%$ of cases [6]. The most frequent AE with FC-SEMSs is spontaneous stent migration. Several attempts have been made to make the stent more stable through the stricture, either fitting it with anti-mi- 


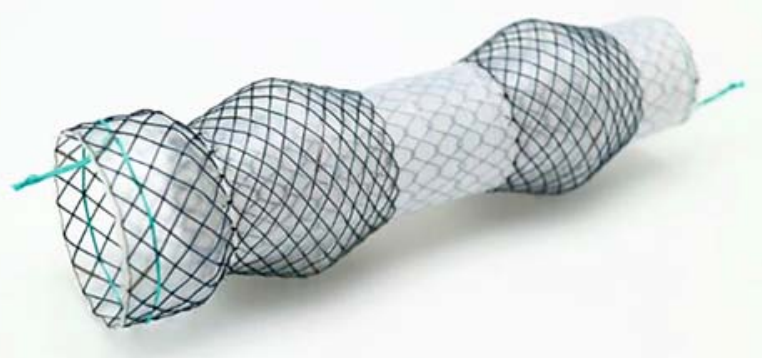

Fig. 1 Beta Niti-S esophageal stent (Source: Taewoong Medical Co., Ltd)

gration systems or anchoring its cranial part to the visceral wall with metal clips.

Beta Niti-S (Taewoong Medical, Seoul, South Korea) is a FCSEMS with an anti-migration system to reduce spontaneous migration ( $\triangleright$ Fig. 1) [7]. This nitinol stent has a proximal head and body with unfixed cell construction, providing extreme flexibility to fit even into tortuous strictures. A polytetrafluoroethylene (PTFE) membrane covers the whole stent, with a silicone double-layer device to prevent migration in the proximal and distal portions of the stent body. Retrieval strings at both ends allow easy removal.

This stent is specifically designed for esophageal benign strictures and cannot be deployed in rectal or sigmoid strictures because of the high risk of migration related to its shape, with a larger distal and a smaller cranial portion when inserted through the rectum. Therefore, we inverted the proximal-distal ends to release the stent across the colorectal stricture. Inversion was done under the supervision of the Surgical and Gastrointestinal Product Division of the Italian branch of Taewoong (Euromedical s.r.I., San Zeno Naviglio, Italy).

The aim of this prospective, observational pilot study was to report the results of a consecutive series of five patients undergoing placement of the "upside-down" Beta Niti-S FC-SEMS, "custom-made," inverted and reloaded on the deployment device by the factory, so the proximal and distal parts of the stent are inverted before insertion, with the largest end placed above the stricture to contrast peristaltic activity, even when positioning the stent through the rectum.

\section{Patients and methods}

Consecutive patients with either benign refractory or malignant colorectal strictures were prospectively enrolled and treated with the modified "inverted" FC-SEMS in this 6-month pilot study. Strictures less than $5 \mathrm{~cm}$ from the anal verge were not considered eligible for stenting and were excluded. Benign strictures were considered refractory when they still persisted after five unsuccessful balloon dilation procedures up to 16 to $18 \mathrm{~mm}$, carried out at 2-week intervals [8] and/or not treatable by endoscopic cutting of the margins $[9,10]$.

A computerized tomography (CT) scan and barium enema with water-soluble contrast medium were carried out in all pa- tients before the procedure to assess the exact shape, length, and distance from the anus of the stricture, and presence of any leaks or fistulae within it.

All procedures were performed in an elective setting, by expert interventional endoscopists, with patients under deep propofol sedation with anesthesiology assistance. Patients were fasted and prepared with cleansing enemas. The procedures were carried out under fluoroscopic and endoscopic guidance with the patients in a supine position. A flexible gastroscope (Pentax, Tokyo, Japan) was used in all cases to reach the stricture site. Before stent insertion, a water-soluble contrast agent was injected through the endoscope working channel to confirm the morphology, length and degree of the stricture, and to document any leaks or fistulae. Once the narrow tract was reached, a hydrophilic guidewire (Jagwire, Boston Scientific, Natick, Massachusetts, United States) was passed through the stricture into the colonic lumen, withdrawing the endoscope. Balloon dilation was not done either before or after stent deployment to reduce risk of stent migration and intraprocedural perforation $[11,12]$. The "inverted" stent was then introduced over the wire, with the scope reinserted alongside it, choosing the size of the stent according to the length of the stricture and its distance from the anal verge. The length of the stent was calculated to ensure correct expansion above and below the stricture. The endoscope reinserted alongside the stent during the deployment phase enabled the operator to accurately check its placement and the exact distance from the anal verge in case of strictures close to the verge.

After stent deployment, contrast fluoroscopy was repeated to confirm correct stent deployment and expansion, closure of any leak(s), and rule out complications such as perforation. An abdominal plain X-ray was taken 24 hours after stent placement to check correct deployment and expansion of the stent. A full liquid diet was resumed the same day as the procedure and a low-fiber diet as soon as normalization of bowel transit had been verified. Analgesic drugs (paracetamol $1000 \mathrm{mg}$ up to three times a day) were given on patient demand. All patients were discharged the day after the procedure. Early discharge in case of leakage was possible when drainages had been inserted in the days before stent insertion.

Technical success was defined as correct stent deployment and expansion across the stricture, with closure of any leak at the end of the procedure, and persistence of the stent in place for at least 3 weeks. Clinical success was defined as stricture relief with a good diameter, watertight closure of the leak, and persistent relief of symptoms at follow-up.

Early and late AEs, considered as undesirable episodes within 48 hours after the procedure and within 30 days, respectively, were recorded. Perforation and stent migration were considered major complications, while self-limiting bleeding, abdominal pain, and tenesmus were considered minor complications. Clinical outcome was assessed at a minimum of 3 weeks, follow-up.

The institutional ethics committee gave approval for stent modification; all patients gave written informed consent to the colorectal stent procedure and authorized use of data for scientific purposes. 


\section{Results}

Five patients were enrolled in this pilot study: four had a postsurgical anastomotic refractory stricture and one a malignant stricture. In all the patients, six inverted "upside-down" FCSEMSs were placed. All patients were males, ranging in age from 35 to 80 . Two of the four patients with benign postsurgical anastomotic stricture underwent left hemicolectomy for neoplasia, the third patient underwent sigmoidectomy for acute, complicated diverticulitis, and the fourth patient, an anterior resection of the rectum. Strictures were high-grade (residual lumen $7 \mathrm{~mm}$ or less) in all cases, sited from 5 to 15 $\mathrm{cm}$ from the anal verge. In two cases, we observed a $1-\mathrm{cm}$ long stenosis, in the other two cases, a 2-cm-long and in one case, the neoplastic one, a 4-cm-long stricture. One patient also presented with a concomitant fistula.

Stricture had persisted in three patients for at least 10 weeks since the initial diagnosis and they had undergone five repeated unsuccessful balloon dilations at 2-week intervals. In one patient, balloon dilation was followed by FC-SEMS placement, which was unsuccessful because of stent spontaneous migration within 1 week.

A patient presented a concomitant fistula secondary to an abdominal abscess percutaneously drained. In that case, no pneumatic dilation was performed, whereas two FC-SEMSs were placed unsuccessful, with early spontaneous migration.

One patient had a rectal-sigmoid low-grade, 4-cm-long stricture due to locally advanced neoplasia, with the distal margin $15 \mathrm{~cm}$ from the anal verge. FC-SEMS placement was planned to permit neoadjuvant chemo-radiotherapy.

The inverted "upside-down" FC-SEMS was successfully deployed in all five patients with no early major and minor complications. One patient with a stricture close to the anal verge $(5 \mathrm{~cm})$ initially reported pain, which was responsive to analgesic therapy, and persistent tenesmus. In the patient with concomitant anastomotic stricture and fistula, percutaneous drainage diminished markedly 24 hours after stent placement.

At 3-week follow-up, stents were still in place and patent in all cases and the patients were free from symptoms.

In the patient with persisting tenesmus, the stent was definitively removed (after 3 weeks) and resolution of the stricture was observed ( $>$ Fig. 2, $>$ Fig. 3, $>$ Fig.4).

In the neoplastic patient, preoperative chemo-radiotherapy induced partial resolution of the stricture allowing spontaneous stent migration 2 weeks later. In two cases of post-anastomotic stricture, endoscopy at weeks 6 and 7 showed stenosis resolution after stent removal, with no need to place another stent. In the remaining case, the 6-week check showed incomplete resolution of the stricture after stent removal, so a further 3-week stenting was planned and after this additional period, the stricture had resolved. In the case with concomitant stricture and fistula, the fistula was closed. In the four cases with post-anastomotic strictures, endoscopy showed a hyperplastic tissue reaction with polypoid appearance at the cranial margin of the stent.

All patients underwent additional endoscopic check-ups 2 to 4 weeks after stent deployment, showing persistence of paten-

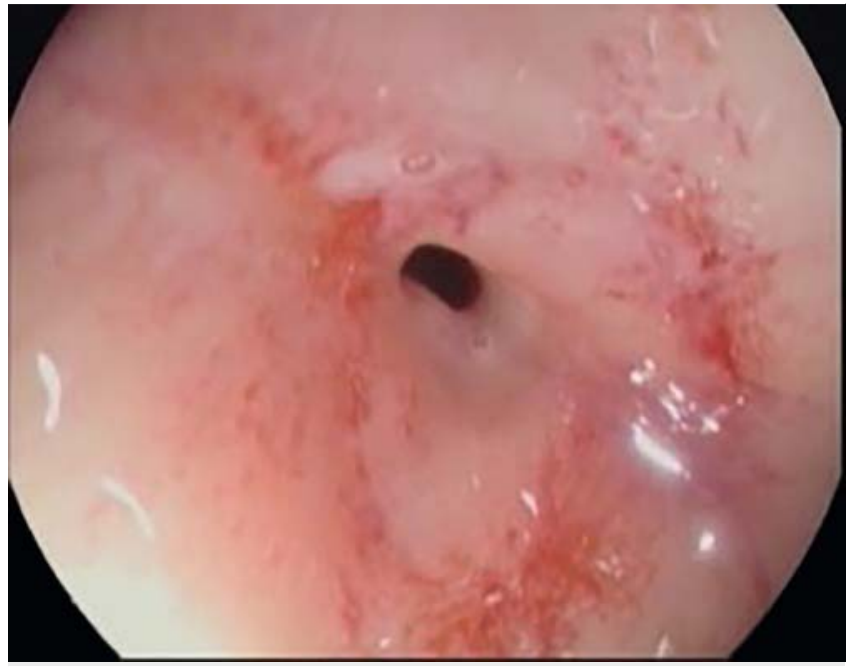

- Fig. 2 Endoscopic image of a benign colorectal stricture
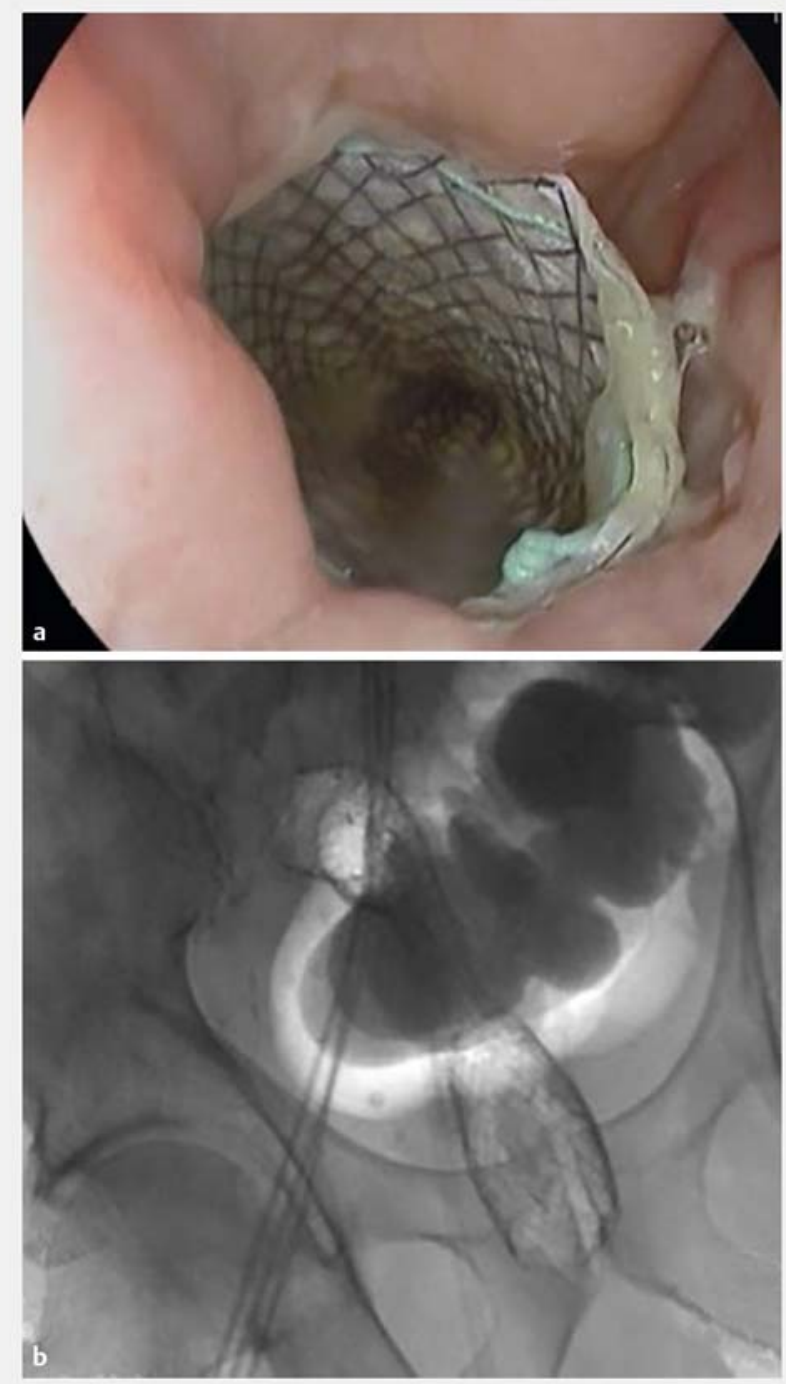

- Fig. 3 a Endoscopic and b fluoroscopic images of an inverted "upside-down" SEMS in place. 


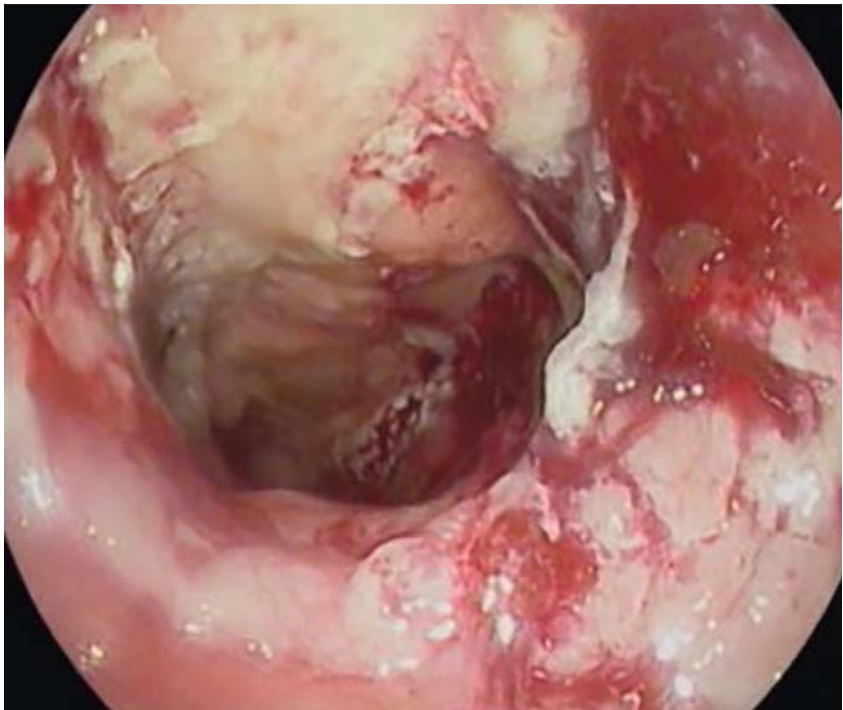

- Fig. 4 Endoscopic image after removal of an inverted "upsidedown" SEMS. cy and reduction of hyperplastic tissue reactions, and were asymptomatic.

Overall, technical and clinical success was observed in all five patients; the FC-SEMS was in place for an average of 6 weeks (range 3-9). The inverted "upside-down" FC-SEMS achieved resolution of strictures and can represent an effective safe alternative to traditional approach, with balloon dilations, reducing hospital admissions and discomfort for the patient with troublesome colorectal strictures.

Data are summarized in $\boldsymbol{\vee}$ Table $\mathbf{1}$.

\section{Discussion}

Management of benign refractory post-surgical anastomotic strictures and malignant colorectal strictures related to undergoing neoadjuvant therapy is still cumbersome. Anastomotic colorectal strictures are frequent after colorectal surgery, very likely caused by local ischemia, infection, or minimal anastomotic leakage [13]. Diverting stoma may further predispose to stricture formation because of the lack of endoluminal dilation by stool.

\begin{tabular}{|c|c|c|c|c|c|c|c|c|c|}
\hline $\begin{array}{l}\text { Patient } \\
\text { age (yr) }\end{array}$ & $\begin{array}{l}\text { Stricture } \\
\text { etiology }\end{array}$ & $\begin{array}{l}\text { Stricture } \\
\text { length }\end{array}$ & $\begin{array}{l}\text { Stricture } \\
\text { grade }\end{array}$ & $\begin{array}{l}\text { Previous } \\
\text { failed treat- } \\
\text { ments }\end{array}$ & $\begin{array}{l}\text { Beta Niti-S } \\
\text { FC-SEMS } \\
\text { used }(\mathrm{mm})\end{array}$ & $\begin{array}{l}\text { Technical } \\
\text { success }\end{array}$ & $\begin{array}{l}\text { Indwell } \\
\text { time } \\
\text { (weeks) }\end{array}$ & $\begin{array}{l}\text { Clinical } \\
\text { follow-up }\end{array}$ & $\begin{array}{l}\text { Adverse } \\
\text { events }\end{array}$ \\
\hline 80 & Postsurgical & $1 \mathrm{~cm}$ & $\leq 7 \mathrm{~mm}$ & $\begin{array}{l}\text { Balloon } \\
\text { Dilations } \\
\text { (5 dilations) }\end{array}$ & $22 \times 100$ & Yes & 7 & $\begin{array}{l}\text { Stricture } \\
\text { resolution }\end{array}$ & $\begin{array}{l}\text { Not } \\
\text { reported }\end{array}$ \\
\hline 40 & Postsurgical & $1 \mathrm{~cm}$ & $\leq 7 \mathrm{~mm}$ & $\begin{array}{l}\text { Balloon } \\
\text { Dilations } \\
\text { ( } 5 \text { dilations) } \\
\text { and FC-SEMS } \\
\text { placement }\end{array}$ & $24 \times 100$ & Yes & 6 & $\begin{array}{l}\text { Stricture } \\
\text { resolution }\end{array}$ & $\begin{array}{l}\text { Not } \\
\text { reported }\end{array}$ \\
\hline 72 & Postsurgical & $2 \mathrm{~cm}$ & $\leq 7 \mathrm{~mm}$ & $\begin{array}{l}\text { Balloon } \\
\text { Dilations } \\
\text { ( } 5 \text { dilations) }\end{array}$ & $26 \times 100$ & Yes & 3 & $\begin{array}{l}\text { Stricture } \\
\text { resolution }\end{array}$ & $\begin{array}{l}\text { Persistent } \\
\text { tenesmus, } \\
\text { resulting } \\
\text { in early } \\
\text { removal }\end{array}$ \\
\hline 35 & $\begin{array}{l}\text { Postsurgical } \\
+ \text { fistula }\end{array}$ & $2 \mathrm{~cm}$ & $\leq 7 \mathrm{~mm}$ & $\begin{array}{l}2 \text { FC-SEMSs } \\
\text { placements }\end{array}$ & $\begin{array}{l}24 \times 100 \\
26 \times 100\end{array}$ & Yes & 9 & $\begin{array}{l}\text { Stricture and } \\
\text { fistula resolu- } \\
\text { tion (A second } \\
\text { stent was } \\
\text { placed, due to } \\
\text { incomplete } \\
\text { stricture reso- } \\
\text { lution after } \\
6 \text { weeks) }\end{array}$ & $\begin{array}{l}\text { Not } \\
\text { reported }\end{array}$ \\
\hline 69 & Neoplasia & $4 \mathrm{~cm}$ & $\leq 7 \mathrm{~mm}$ & $\begin{array}{l}\text { FC-SEMS } \\
\text { placement }\end{array}$ & $24 \times 100$ & Yes & 5 & $\begin{array}{l}\text { Bridge-to- } \\
\text { neoadjuvant } \\
\text { therapy }\end{array}$ & $\begin{array}{l}\text { Stent mi- } \\
\text { gration in- } \\
\text { duced by } \\
\text { response to } \\
\text { neoadju- } \\
\text { vant che- } \\
\text { moradia- } \\
\text { tion }\end{array}$ \\
\hline
\end{tabular}


Benign strictures are mainly treated initially with balloon dilation $[8,14,15]$. This treatment, troublesome for the patient and with short-term relief, generally requires multiple sessions (up to five) and repeated hospital admissions over several weeks, with increasing costs. Moreover, dilation cannot be done in cases of concomitant leaks or fistulae. Making multiple shallow incisions in the stricture to break down the membranous circular scar is a valid alternative to balloon dilation [9, $10]$, but it is a high-risk maneuver in case of strictures longer than 1 to $2 \mathrm{~cm}$.

In case of endoscopic failure or stricture recurrence, the remaining treatment options are placement of SEMS or revisional surgery. Revisional surgery may be very difficult on account of adhesions, local inflammation, and stricture location (in most cases, in the lower rectum); for these reasons, today it is not considered the first alternative. Therefore, SEMS placement, applying a constant radial force to the stricture for a longer time, appears to be the only realistic alternative for managing refractory strictures, even if complication and re-obstruction rates are not negligible (up to $12 \%$ and $14 \%$, respectively) [16, 17].

Uncovered SEMSs have been proposed as a palliative option in patients with malignant disease or who are unfit for surgery. These stents are also associated with a high rate of complications, mainly perforation, which has been reported in about $12 \%$ of cases [3].

Partially covered SEMSs (PC-SEMSs) need to be removed within a short period, 2 or 3 weeks, not enough to resolve the stricture, which results in need for further additional stenting. Reports show a high incidence of complications when removing these stents, such as severe bleeding or perforation [18], or the need to deploy a FC-SEMS for some days to remove both stents (the so-called "stent-in-stent" technique) [19].

FC-SEMSs and biodegradable polymer stents are the best options for temporary stenting. Stents made of biodegradable materials seem to overcome the shortcomings of the FC-SEMS, especially spontaneous migration; they do not require any removal procedure, and have been proved effective in the treatment of colorectal strictures [20], although a retrospective analysis documented a high risk of migration and a clinical success in fewer than $50 \%$ of patients [21]. Furthermore, these stents are expensive, may induce a marked mucosal hyperplastic reaction all along their length, and cannot be used if there are leaks or fistulae.

FC-SEMSs are less expensive than biodegradable ones, they can be left in place for a longer period, and they are easily removed. Hyperplastic tissue reactions occur only at the proximal margin of the stent. However, FC-SEMSs have a very high rate of spontaneous migration in the colon-rectum (up to $40 \%$ of cases) [6], due to peristaltic activity and stent shape, especially in patients with benign or non-infiltrating strictures, even when a bumper-shaped SEMS is used. To avoid risk of spontaneous migration, we inverted the proximal and distal parts of an esophageal Beta Niti-S FC-SEMS upside down and reloaded it on the deployment device, so as to have the largest end above the stricture when introducing the stent through the rectum, and assessed the efficacy of this custom-made device in treat- ment of four benign refractory anastomotic colorectal strictures and one neoplastic stricture scheduled for neoadjuvant therapy. The rationale for use of the inverted FC-SEMS in a neoplastic low-grade stricture (residual lumen up to $12 \mathrm{~mm}$ ) was to allow the patient to undergo chemotherapy without risk of occlusion and permitting spontaneous migration of the stent in case of response to therapy, with reduction of the stricture.

The inverted "upside-down" esophageal Beta Niti-S FC-SEMS proved effective in all these cases. It remained in place for up to 7 weeks after insertion in anastomotic strictures, with resolution of the strictures and closure of the fistula, while in the cancer patient it migrated spontaneously after resolution of the stricture by chemotherapy, 5 weeks after insertion. Stent removal was easy and without complications in all cases.

This preliminary experience showed that, in patients with refractory anastomotic strictures, a FC-SEMS with the characteristics obtained by inverting the esophageal Beta Niti-S FC-SEMS appeared to be a better and less expensive option than the currently available FC-SEMSs for colorectal stenting. We are now awaiting a new FC-SEMS specifically designed for colorectal strictures, with a cranial margin large enough to contrast peristaltic activity and prevent spontaneous migration. Although our data refer to a pilot study, the results permit us to propose use of this stent after three unsuccessful balloon dilation attempts, to shorten the time between occurrence of the stricture and its resolution.

\section{Competing interests}

Dr. Antonucci is part of the Surgical and Gastrointestinal Product Division of the Italian branch of Taewoong (Euromedical s.r.I., San Zeno Naviglio, Italy).

References

[1] Suchan KL, Muldner A, Manegold BC. Endoscopic treatment of postoperative colorectal anastomotic strictures. Surg Endosc 2003; 17: $1110-1113$

[2] Dai Y, Chopra SS, Wysocki WM et al. Treatment of benign colorectal strictures by temporary stenting with self-expanding stents. Int J Colorectal Dis 2010; 25: 1475-1479

[3] Currie A, Christmas C, Aldean H et al. Systematic review of self-expanding stents in the management of benign colorectal obstruction. Colorectal Dis 2013; 16: 239-245

[4] Forshaw M, Sankararajah D, Stewart M et al. Self-expanding metallic stents in the treatment of benign colorectal disease: indications and outcomes. Colorectal Dis 2006; 8: $102-111$

[5] Caruso A, Conigliaro R, Manta R et al. Fully covered self-expanding metal stents for refractory anastomotic colorectal strictures. Surg Endosc 2015; 29: 1175 - 1178

[6] Cereatti F, Fiocca F, Dumont JL et al. Fully covered self-expandable metal stent in the treatment of postsurgical colorectal diseases: outcome in 29 patients. Therap Adv Gastroenterol 2016; 9: 180 - 188

[7] Ji JS, Lee BI, Kim HK et al. Antimigration property of a newly designed covered metal stent for esophageal stricture: an in vivo animal study. Gastrointest Endosc 2011; 74: 148-153 
[8] de Wijkerslooth LR, Vleggaar FP, Siersema PD. Endoscopic management of difficult or recurrent esophageal strictures. Am J Gastroenterol 2011; 106: 2080 - 2091

[9] Chen T, Hsu WL. Successful treatment of colorectal anastomosis stricture by using sphincterotomes. Front Surg 2014; 1: 22

[10] Osera S, Ikematsu H, Odagaki T et al. Efficacy and safety of endoscopic radial incision and cutting margins for benign severe anastomotic stricture after surgery for lower rectal cancer (with video). Gastrointest Endosc 2015; 81: 770-773

[11] Bonin E, Baron T. Update on the indications and use of colonic stent. Curr Gastroenterol Rep 2010; 12: 374-382

[12] Vanbiervliet G, Bichard P, Demarquay J et al. Fully covered self-expanding metal stents for benign colonic strictures. Endoscopy 2013; 45: $35-41$

[13] Påhlman L, Glimelius B, Frykholm G. Ischaemic strictures in patients treated with a low anterior resection and perioperative radiotherapy for rectal carcinoma. Br J Surg 1989; 76: 605-606

[14] Virgilio C, Cosentino S, Favara C et al. Endoscopic treatment of postoperative colonic strictures using an achalasia dilator: short-term and long-term results. Endoscopy 1995; 27: 219-222
[15] Park CH, Yoon JY, Park SJ et al. Clinical efficacy of endoscopic treatment for benign colorectal stricture: ballon dilation versus stenting. Gut and Liver 2015; 9: $73-79$

[16] van Halsema EE, van Hooft JE, Small AJ et al. Perforation in colorectal stenting: a meta-analysis and a search for risk factors. Gastrointest Endosc 2014; 79: 970 - 982

[17] Currie A, Christmas C, Aldean H et al. Systematic review of self-expanding stents in the management of benign colorectal obruction. Colorectal Dis 2014; 16: 239-245

[18] Small A, Young-Fadok T, Baron T. Expandable metal stent placement for benign colorectal obstruction: outcomes for 23 cases. Surg Endosc 2008; 22: $454-462$

[19] Yang D, Seo M, Lee $\mathrm{H}$ et al. Stent-in-stent technique and endoscopic resection of granulation tissue to remove a migrated metal duodenal stent embedded in the colon. Endoscopy 2014; 46: E159-E160

[20] Rejchrt S, Kopacova M, Brozik J et al. Biodegradable stents for the treatment of benign stenosis of the small and large intestines. Endoscopy 2011; 43: $911-917$

[21] Repici A, Pagano N, Rando G et al. A retrospective analysis of early and late outcome of biodegradable stent placement in the management of refractory anastomotic colorectal strictures. Surg Endosc 2013; 27: $2487-2491$ 